\title{
HIGH ALTITUDE PLATFORM STATIONS IN DESIGN WIRELESS COMMUNICATION SYSTEM FOR COVER THE SPECIFIC AREA
}

\author{
Yousif Mohsin Hasan, \\ University of Al-Qadisiyah, College of Engineering, Iraq. \\ E-mail:yousif.hasan@qu.edu.iq
}

\begin{abstract}
Received on 24 October 2017 Accepted on 13 December 2017 Published on 15 March 2018
DOI: $10.30772 /$ qjes.v10i4.490
\end{abstract}

\begin{abstract}
This paper explains how to design a wireless communication system via high altitude platform stations HAPS to cover the specific area (Using Diwaniyah city area as a model). High altitude platform station HAPS is unmanned airplane provides the wireless communication service to the wider area. It is designed to work at high altitude between $(17-22 \mathrm{Km})$ and coverage area $400 \mathrm{Km}$. This study illustrated for calculating the cochannel interference between HAPS ground station with a terrestrial station and satellite station. Free space losses for a HAPS ground station has been applied to meet the geographic of Diwaniyah city. In addition, explaining the relationship between elevation angles with the radius of the coverage area. Interference mitigation techniques have been given, such as improving the antenna radiation pattern, then it proposed the elevation angle for the HAPS's ground stations to reduce an interference between HAPS network with Fixed Service (FS) and fixed satellite service (FSS). Finally, this study explains the relationship between elevation angles with the radius of the coverage area. For more reliability, the Scenario for covers the city of Diwaniya. Two ground stations have been proposed to connect with high-altitude platform station.
\end{abstract}

Keywords: wireless communication system, High Altitude Platform Stations (HAPS) , cochannel interference, Interference to Noise Ratio I/N, separation distance, HAPS coverage area.

\section{INTRODUCTION}

High Altitude Platform Stations (HAPS) is one of the new technologies that provide the wireless communication service. This technology can be performing the service of the terrestrial station and satellite system. The service of high altitude platform station (HAPS) includes wireless communication, broadband communication, weather monitoring, security monitoring and data of city map collection. The High-Altitude Platform Station (HAPS) is situated between 17 and $22 \mathrm{Km}$ above ground [2]. HAPS coverage area about $200 \mathrm{Km}$ to $500 \mathrm{Km}$ depend on the specific area which has been chosen to design these technologies [12]. One of the advantages of using high altitude platform station can provide a wide coverage area. Single HAPS can be covering an area equivalent to 258 ground terrestrial towers [1]. High altitude platform station technology has been several advantages compared with satellite and terrestrial services such as low propagation delay compares with satellite and wide area coverage compare with terrestrial services [9]. HAPS coverage area, depending on the altitude of HAPS and the elevation angle. (Figure 1) describes how HAPS can carry a large variety of wireless communications payload which provide a high capacity of endusers of broadband service. 


\section{AL-QADISIYAH JOURNAL FOR ENGINEERING SCIENCES}

Vol. 10 , No. 4

ISSN: $1998-4456$

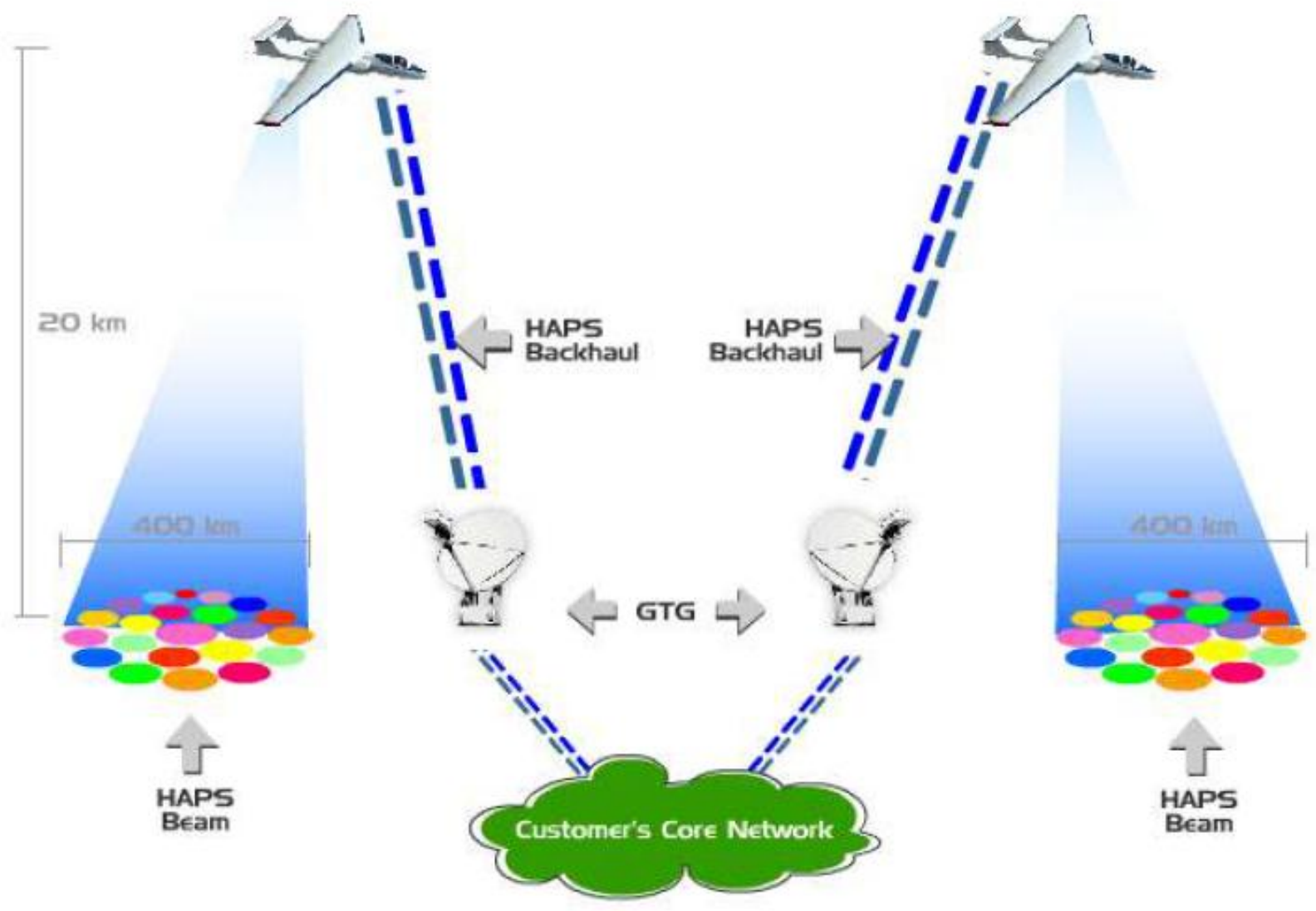

Figure 1: Network architecture of HAPS [10].

\section{INTERFERENCE MITIGATION TECHNIQUE}

Thus, general interference mitigation techniques must be taken into our consideration for the development of a system using HAPS [5].

\subsection{INCREASING THE MINIMUM ELEVATION ANGLE (ELV. ANGLE)}

"Interference from the fixed satellite service (FSS)"[5] ground station to the HAPS ground stations that between FS ground stations and HAPS ground station can be reduced by increasing the minimum elevation angle of the HAPS ground station.

\subsection{IMPROVEMENT OF RADIATION PATTERNS OF ANTENNA STATIONS}

This technique can be reduced interference from HAPS airship to the space satellite part by forming a pattern of each beam of a multi beam antenna on the board HAPS airship, (Figure 2) explains the pattern shaping improves the main lobe and side lobes characteristic [6]. 


\section{AL-QADISIYAH JOURNAL FOR ENGINEERING SCIENCES}

Vol. 10 , No. 4

ISSN: $1998-4456$

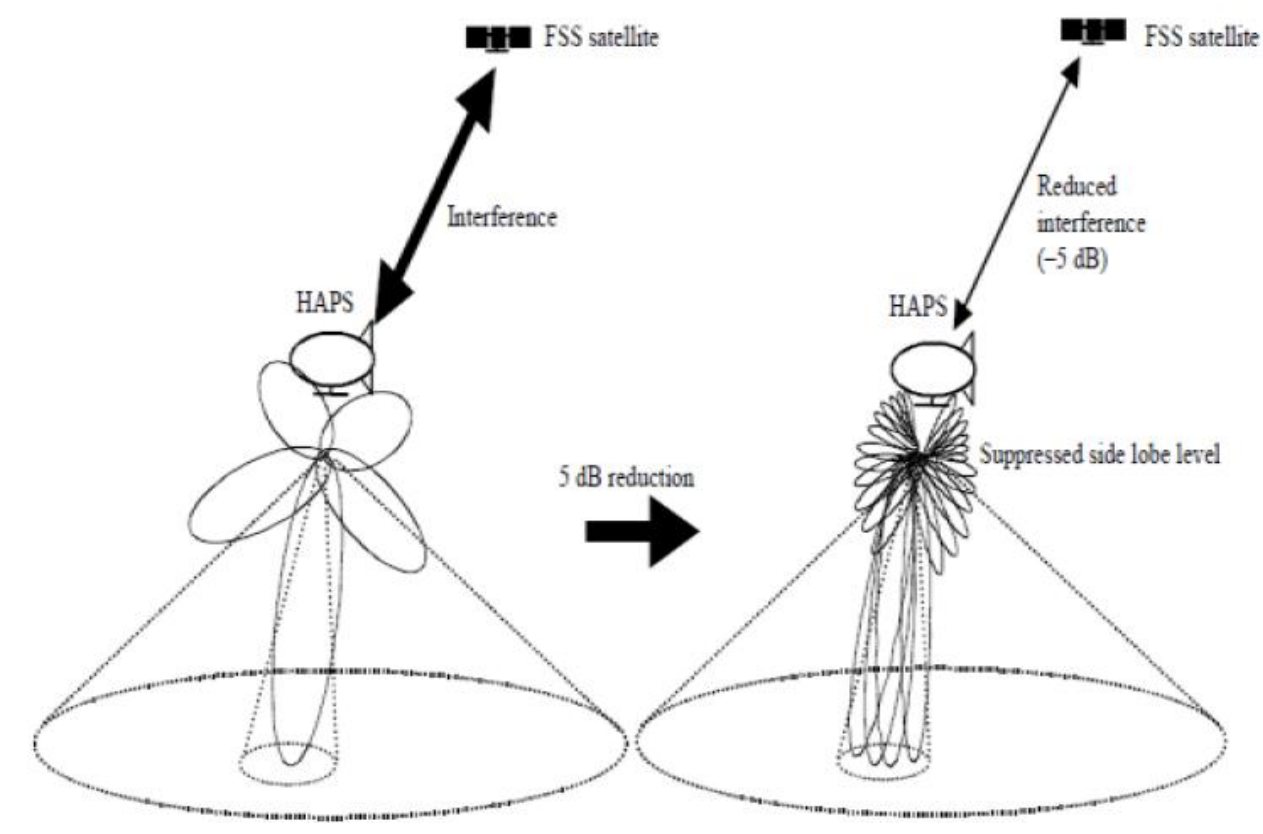

Figure 2: Main lobe and side lobes characteristic (improvement antenna radiation pattern).

\subsection{DYNAMIC CHANNEL ASSIGNMENT (DCA)}

It is to reduce the interference; this mitigation is to search un-use frequencies, not to give interference to another service and not so as to be received from another service. When wireless communication system operating base on demand assignment, DCA scheme is using self-control ineffective for sharing with another service. [4]

\subsection{AUTOMATIC TRANSMISSION POWER CONTROL (ATPC)}

In the wireless communication system use a high-bandwidth, and system design consider the attenuation of rain. To compensate for attenuation, is to increase the transfer of power from the rain value. ATPC has the potential to control the production of energy in monitoring the weather or receive power. Transmission power is increasing with rain condition and its decreasing with clear sky condition [5].

\section{HAPS INTERFERENCE AND FREE SPACE LOSS EVALUATION} equations.

For the calculation interference from the HAPS ground stations to FWA stations used following

"The interference from HAPS ground Station to an FWA station is obtained by the equation (1)" [13]

$$
I=P_{T x_{-} G S}-L_{f T x_{-} G S}+G_{T x_{-} G S}\left(\theta_{H_{-} F}\right)-L_{s}-L_{A t m}-L_{O b s}+G_{R x_{-} F W A}\left(\theta_{F_{-} H}\right)-L_{f R x_{-} F W A}
$$

I is Interference, $P_{T x_{-} G S}$ Transmission power for HAPS's ground stations in (dB), $L_{f T x_{-} G S}$ feeder loss of HAPS ground station (dB), $G_{T x_{-} G S}\left(\theta_{H_{-} F}\right)$ antenna gain of HAPS ground station, $L_{s}$ free space path losses between FWA stations and HAPS ground station (dB), 


\section{AL-QADISIYAH JOURNAL FOR ENGINEERING SCIENCES}

Vol. 10, No. 4

ISSN: $1998-4456$

$L_{\text {Atm }}$ Atmosphere absorption loss between HAPS ground station and FWA station(dB), $G_{R_{-} F W A}\left(\theta_{F_{-} H}\right)$ Receiving antenna gain of FWA station $(\mathrm{dBi})$ and $L_{f R x_{-} F W A}$ is the feeder losses in FWA stations (dB).

The free space path losses between HAPS ground stations and FWA stations is given by equation (2)

$$
L_{s}=\frac{4 \pi d * 1000}{\tau}
$$

Where $d$ is the distance between HAPS and FWA station in $(\mathrm{Km}),{ }^{\tau}$ is a wavelength in $(\mathrm{m})$ and the interference to noise ratio $(\mathrm{I} / \mathrm{N})$ was obtained by equation (3) [8].

$$
\frac{I}{N}=I-10 \log \left(293 * K * 10^{N F / 10^{* 10^{6}}}\right) d B(3)
$$

Where $\mathrm{K}$ is Boltzmann constant $=1.38 \times 10^{\wedge}-23(\mathrm{~J} / \mathrm{K})$, NF is noise figure $(\mathrm{dB})$.

\section{METHODOLOGY}

\subsection{LOCATION}

Diwaniyah Coordinates longitude $31^{\circ} 59^{\prime} 15^{\prime \prime} \mathrm{N}$ and latitude $44^{\circ} 55^{\prime} 42^{\prime \prime} \mathrm{E}$, according to the map of Diwaniyah city. The location of HAPS to the center of the coverage area after studying these area is shown in (Figure 3). According to the whole area of Diwanyiah city, the footprints of coverage area shown in (Google map), the area of Diwaniyah city center is (1212 Sq. Km).

\subsection{SYSTEM PARAMETERS}

The parameters of HAPS and FS systems are Summary in (Table 1) to covering a Diwaniyah city area. In (Table 1) shows the angle and corresponding ground coverage area have been measured from nadir.

Table 1: Parameters of HAPS system.

\begin{tabular}{|l|c|}
\hline HAPS altitude & $20 \mathrm{~km}$ \\
\hline Antenna gains of a HAPS ground station & $35 \mathrm{dBi}$ \\
\hline Availability of HAPS system & $99.4 \%$ \\
\hline Minimum elevation angle of HAPS ground stations & $30^{\circ}$ \\
\hline Estimated number of HAPS & 1 \\
\hline Required $E b / N_{0}$ for BER $=1 \times 10^{-6}$ & $5.5 \mathrm{~dB}$ \\
\hline link margin of HAPS system & $3 \mathrm{~dB}$ \\
\hline
\end{tabular}



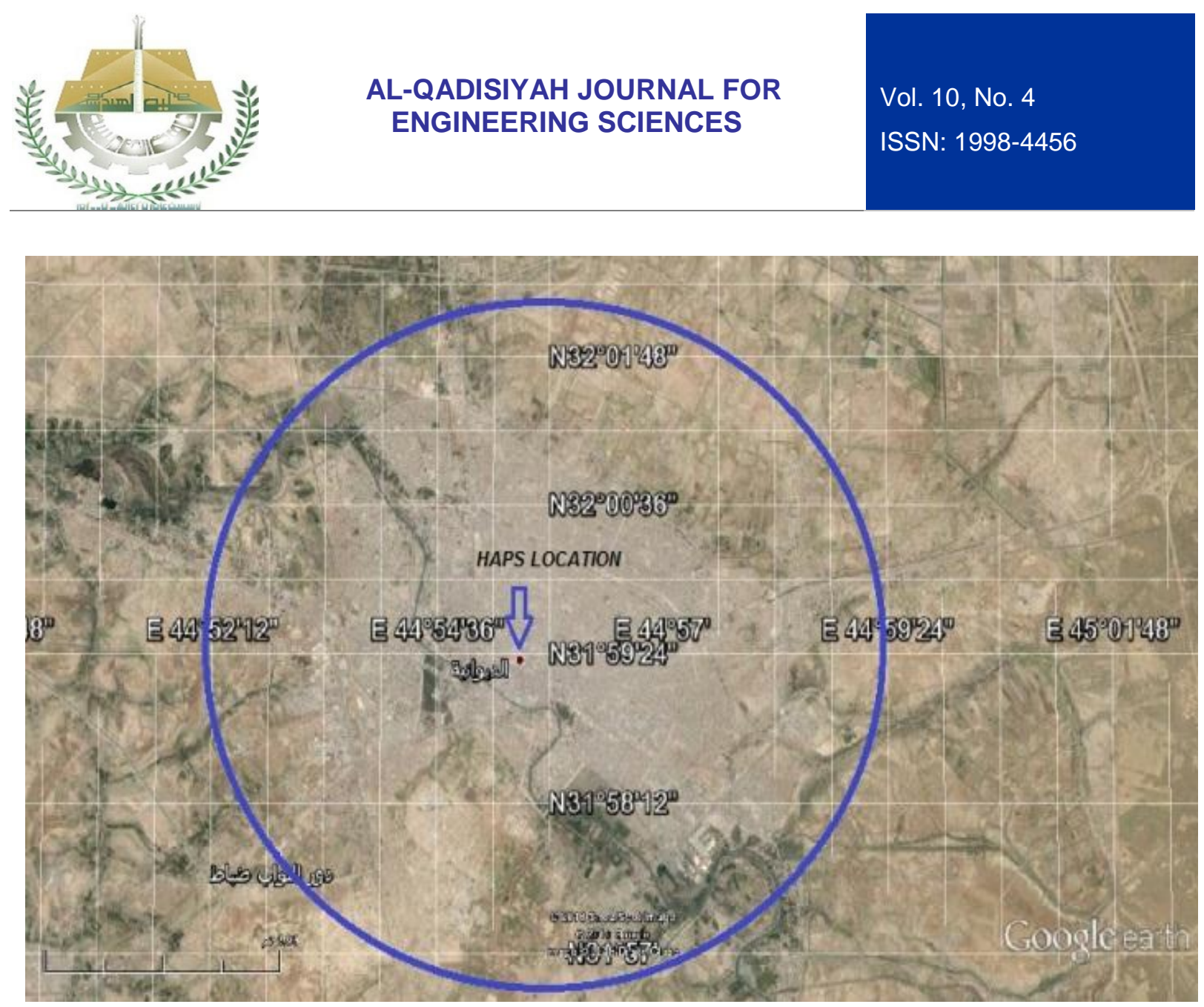

Figure 3: HAPS coverage area in Diwaniyah city's map.

\subsection{ALTITUDE SELECTION FOR HAPS SYSTEM}

The major challenge on the altitude selection for HAPS is the wind speed. An operating altitude of HAPS between $17 \mathrm{Km}$ and $22 \mathrm{Km}$ because the wind speed is the minimum as shown in (Figure 4) [14]. At altitudes of $20 \mathrm{~km}$, the air masses can be considered relatively stationary with very slow winds. The altitude of HAPS depends on wind speed. In this case it was chosen altitude of HAPS to Diwaniyah city center is above $20 \mathrm{Km}$ it is enough to cover this area. 


\section{AL-QADISIYAH JOURNAL FOR ENGINEERING SCIENCES}

Vol. 10 , No. 4

ISSN: $1998-4456$

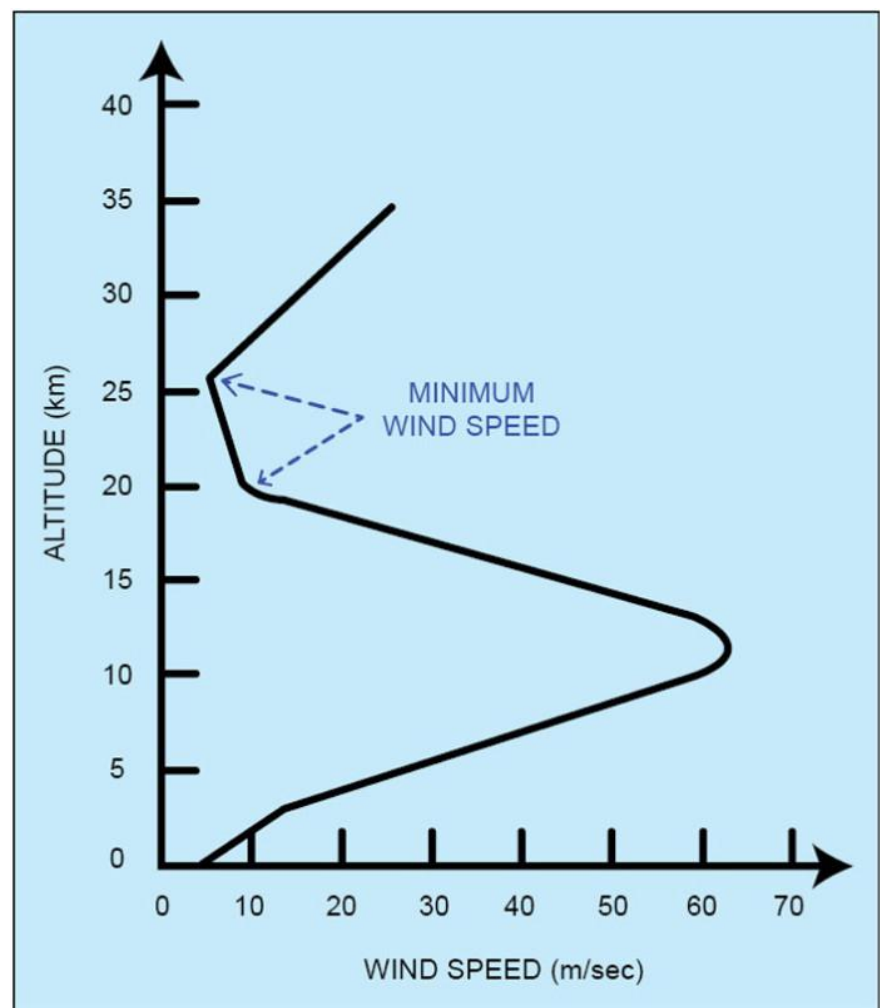

Figure 4: Wind speed $(\mathrm{m} / \mathrm{s})$ VS altitude $(\mathrm{Km})[14]$.

\subsection{HAPS COVERAGE AREA}

The coverage area of the high altitude platform station (HAPS) is depending on altitude and elevation angle of the antenna. One HAPS airship can be offer remarkable coverage measurement $400 \mathrm{Km}$ distance of the ground area instead of 258 ground terrestrial towers [2]. (Figure 5) have been plotted with Matlab program, it explains the relationship between the elevation angle and the radius of the coverage area. reducing elevation angle lead to increase the radius of the coverage area it is an inverse relationship.

From table1. the elevation angle of the HAPS ground station for Diwanyiah city using the UAC coverage area will be at $30^{\circ}, 60^{\circ}$ and $90^{\circ}$ with altitude $20 \mathrm{Km}$, so the distance of the HAPS ground station will be:

$$
\begin{aligned}
& d 1=\frac{\text { Altitude }}{\tan (\text { ele. angle })}=\frac{20 \mathrm{Km}}{\tan (30)}=34.614 \mathrm{Km}(4) \\
& d 2=\frac{\text { Altitude }}{\tan (\text { ele. angle })}=\frac{20 \mathrm{Km}}{\tan (60)}=11.547 \mathrm{Km}(5)
\end{aligned}
$$




\section{AL-QADISIYAH JOURNAL FOR ENGINEERING SCIENCES}

Vol. 10 , No. 4

ISSN: $1998-4456$

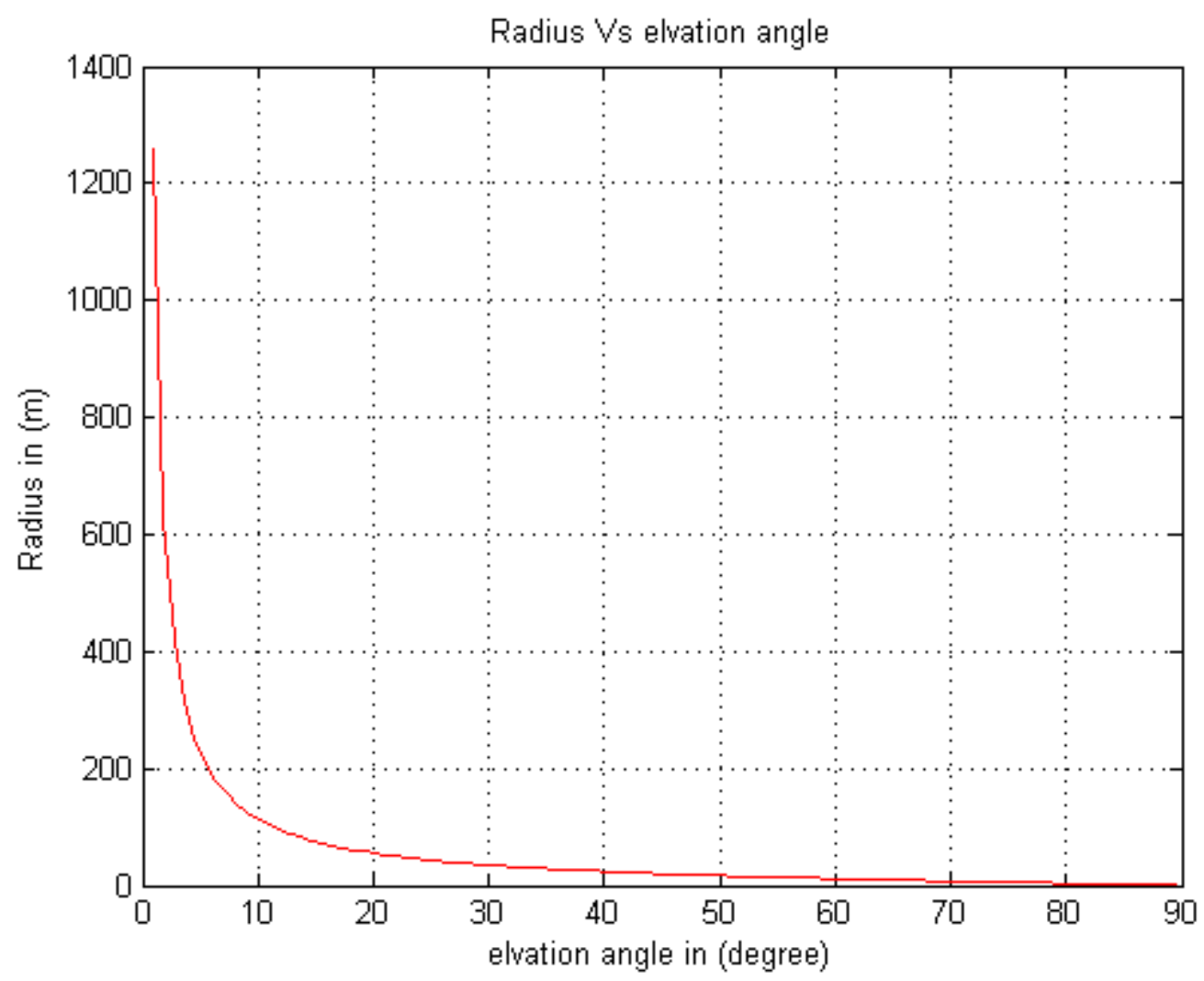

Figure 5: Radius VS elevation angle at altitude $20 \mathrm{Km}$.

\subsection{INTERFERENCE TO NOISE RATIO I/N UNDER CLEAR SKY CONDITION}

To calculate interference to noise ratio $\mathrm{I} / \mathrm{N}$ must find the free space loss Ls by using equation (2) and calculate interference power (I) using equation (1). (Figure 6) show the antenna pattern for the HAPS ground station while the typical link budget for the HAPS system is given in (table 2) used $28 / 31.28 \mathrm{GHz}$ under clear sky conditions [13]. Both (table 2) and (Figure 6) are adopted the value of parameter regard the HAPS ground in equation (1). 


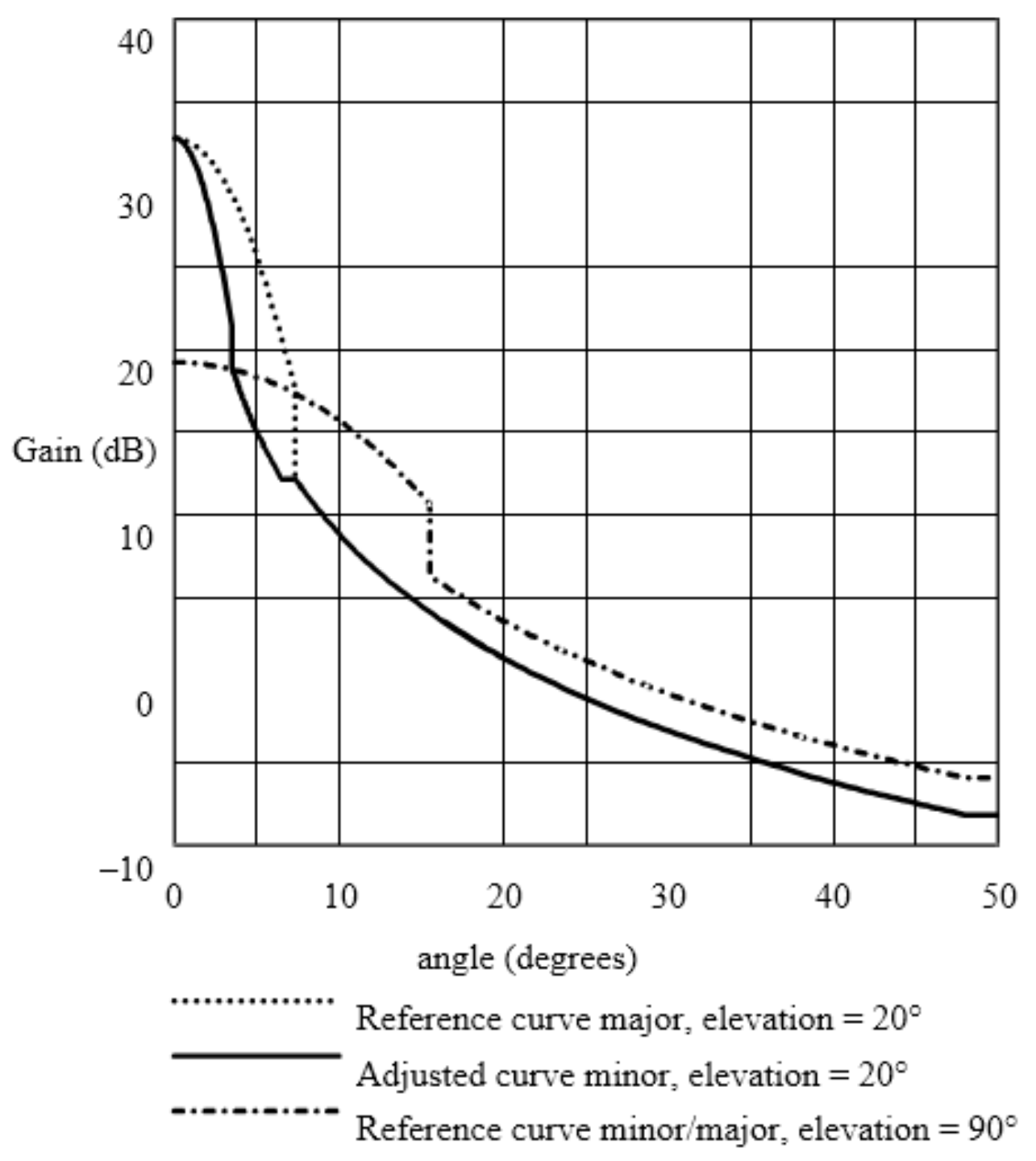

Figure 6: HAPS antenna pattern. 
AL-QADISIYAH JOURNAL FOR ENGINEERING SCIENCES
Vol. 10, No. 4

ISSN: $1998-4456$

Table 2: Link budget for HAPS system at 20Km altitude, clear sky conditions [13].

\begin{tabular}{|c|c|c|c|c|}
\hline & Up link & Down link & Up link & Down link \\
\hline Elevation angles (in degree) & \multicolumn{2}{|c|}{$20^{\circ}$} & \multicolumn{2}{|c|}{$90^{\circ}$} \\
\hline Frequency $(\mathrm{F})$ & $31.28 \mathrm{GHz}$ & $28 \mathrm{GHz}$ & $31.28 \mathrm{GHz}$ & $28 \mathrm{GHz}$ \\
\hline Bandwidth(BW) & $20 \mathrm{MHz}$ & $20 \mathrm{MHz}$ & $20 \mathrm{MHz}$ & $20 \mathrm{MHz}$ \\
\hline $\begin{aligned} & \text { Transmition ofantenna: } \\
& \text { - } \text { power o/p }(\mathrm{dBW}) \\
& \text { - } \text { feeder losses }(\mathrm{dB}) \\
& \text { - } \text { Gain }(\mathrm{dBi}) \\
& \text { - } \text { e.i.r.p. }(\mathrm{dBW}) \\
& \text { - } \text { e.i.r.p(dB(W/MHz)) }\end{aligned}$ & $\begin{array}{c}-16.3 \\
0.5 \\
35 \\
18.2 \\
5.2 \\
\end{array}$ & $\begin{array}{c}-14.5 \\
0.5 \\
29.5 \\
14.5 \\
1.5 \\
\end{array}$ & $\begin{array}{c}-16.3 \\
0.5 \\
35 \\
18.2 \\
5.2 \\
\end{array}$ & $\begin{array}{c}-15.2 \\
0.5 \\
16.5 \\
0.7 \\
-12.3 \\
\end{array}$ \\
\hline Path length $(\mathrm{km})$ & 58.50 & 58.50 & 20.0 & 20.0 \\
\hline $\begin{array}{l}\text { Free space path losses }(\mathrm{dB}) \\
\text { Rain atténuation }(\mathrm{dB}) \\
\text { Availability in the zone } \mathrm{M}(\%) \\
\text { Atmospheric gases attenuation }(\mathrm{dB})\end{array}$ & $\begin{array}{c}157.7 \\
0 \\
100 \\
0.4\end{array}$ & $\begin{array}{c}156.7 \\
0 \\
100 \\
0.4\end{array}$ & $\begin{array}{c}148.4 \\
0 \\
100 \\
0\end{array}$ & $\begin{array}{c}147.4 \\
0 \\
100 \\
0\end{array}$ \\
\hline $\operatorname{Pfd}\left(\mathrm{dB}\left(\mathrm{W} / \mathrm{m}^{2} \cdot \mathrm{MHz}\right)\right)$ & & -105.2 & & -109.3 \\
\hline $\begin{array}{l}\text { Receiving antenna: } \\
\text { - } \text { Gain }(\mathrm{dBi}) \\
\text { - } \text { Feeder losses }(\mathrm{dB}) \\
\text { - } \text { Received power }(\mathrm{dBW}) \\
\text { - } \text { Noise temperature in }(\mathrm{K}) \\
\text { - } \text { Noise temperature in }(\mathrm{dB}(\mathrm{W} / \mathrm{Hz})) \\
\text { - Interference power }(\mathrm{dB}(\mathrm{W} / \mathrm{MHz})) \\
\text { - } \\
(I / N=10 \%) \\
\text { receiver losses technical }(\mathrm{dB})\end{array}$ & $\begin{array}{c}29.5 \\
0.5 \\
-110.9 \\
700 \\
-200.2 \\
-150.2 \\
2.5\end{array}$ & $\begin{array}{c}35 \\
0.5 \\
-108.1 \\
500 \\
-201.6 \\
-151.6 \\
2.5\end{array}$ & $\begin{array}{c}16.5 \\
0.5 \\
-114.2 \\
700 \\
-200.2 \\
-150.2 \\
2.5\end{array}$ & $\begin{array}{c}35 \\
0.5 \\
-112.2 \\
500 \\
-201.6 \\
-151.6 \\
2.5\end{array}$ \\
\hline $\mathrm{C} / \mathrm{N}_{0}$ available $(\mathrm{dB}(\mathrm{Hz}))$ & 86.30 & 90.60 & 83.00 & 86.50 \\
\hline $\begin{array}{l}\text { UserDataRate UDR (Mbit/s) } \\
\text { UserDataRate UDR (dBHz)) }\end{array}$ & $\begin{array}{l}13.3 \\
71.2\end{array}$ & $\begin{array}{l}13.3 \\
71.2\end{array}$ & $\begin{array}{l}13.3 \\
71.2\end{array}$ & $\begin{array}{l}13.3 \\
71.2\end{array}$ \\
\hline $\begin{array}{l}\text { Required } \\
\text { (BER for QPSK }=10^{-6} \text { ) }\end{array}$ & 10.50 & 10.50 & 10.50 & 10.50 \\
\hline $\begin{array}{l}\text { Coding gains }(\mathrm{dB}) \quad(K=7, r=2 / 3) \\
\text { Necessary } E_{b} / N_{0}(\mathrm{~dB}) \\
\text { Necessary } C / N_{0}(\mathrm{~dB}(\mathrm{~Hz}))\end{array}$ & $\begin{array}{c}5 \\
5.5 \\
76.7\end{array}$ & $\begin{array}{c}5 \\
5.5 \\
76.7\end{array}$ & $\begin{array}{c}5 \\
5.5 \\
76.7\end{array}$ & $\begin{array}{c}5 \\
5.5 \\
76.7\end{array}$ \\
\hline LinkMargin in $(\mathrm{dB})$ & 9.60 & 13.90 & 6.30 & 9.80 \\
\hline
\end{tabular}

Both (Table 3) and (Figure 7) are using to obtain the value of a parameter regarding FWA base station. after calculating interference, can be computed interference to noise ratio $\mathrm{I} / \mathrm{N}$ using equation (3). 
Table 3: Parameters of FWA station.

\begin{tabular}{|l|l|l|}
\hline Parameters & $\mathbf{3 1 . 2 8} \mathbf{~ G H z}$ & $\mathbf{2 8 ~ G H z}$ \\
\hline Transmitting O/P (in dBW) & -3.0 & -3.0 \\
Spectral density O/P (in dB( W/ MHz)) & -6.0 & -6.0 \\
Noise figures (dB) & 7.0 & 8.0 \\
Receiving thermal noise calculating (in dB(W/ MHz)) & -137.0 & -136.0 \\
Antenna gains (indBi) & $37 / 46$ & $36 / 46$ \\
Antenna Pattern depend on & Reco.ITU_R F1245 & Reco.ITU_R F1245 \\
Feeder losses (dB) & zero & Zero \\
Modulation type & 4-FSK. & QPSK. \\
\hline
\end{tabular}

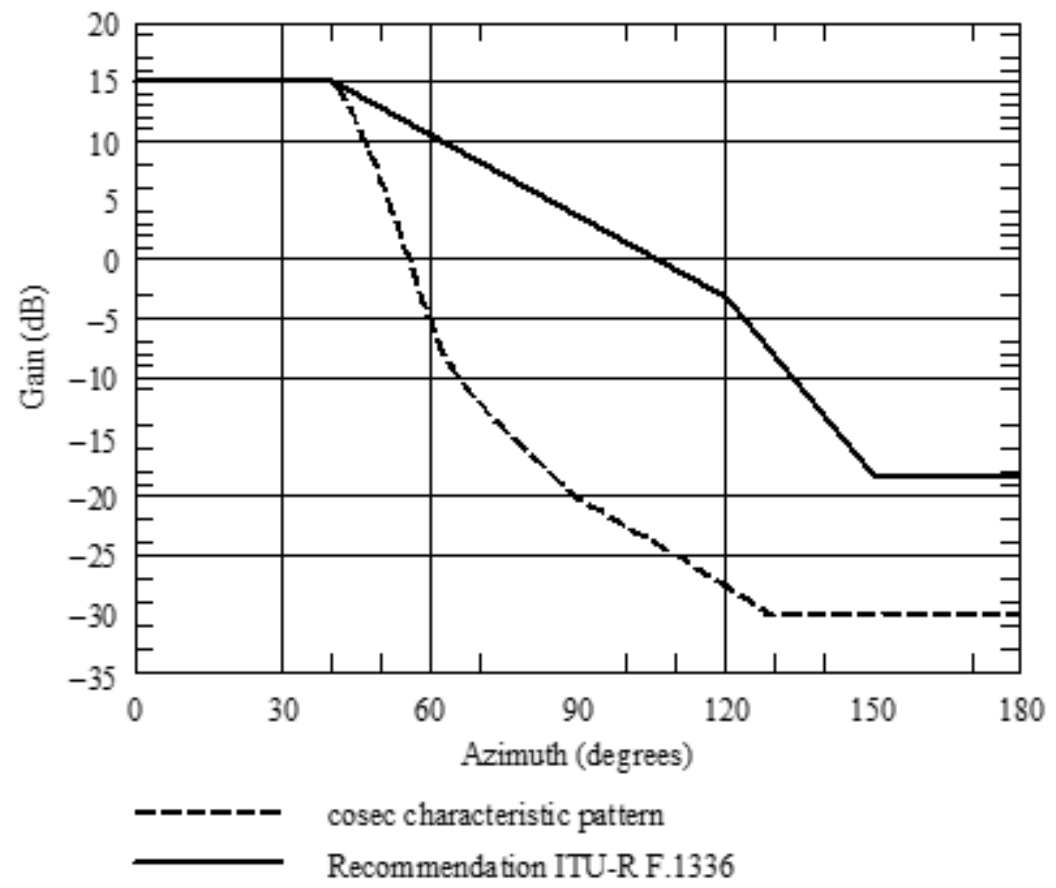

Figure 7: antenna beam pattern in azimuth direction. 


\section{AL-QADISIYAH JOURNAL FOR ENGINEERING SCIENCES}

Vol. 10, No. 4

ISSN: $1998-4456$

\section{RESULT AND DISCUSSION}

Using MATLAB to plot and analysis the graphs for showing the relationship between interference to noise ratio $(\mathrm{I} / \mathrm{N})$, separation distance(d) and the azimuth angles in clear sky condition shown in (Figure 8). The main importance in this survey is to get minimum separation distance necessary to optimize interference to noise ratio, it will be $-10 \mathrm{~dB}$. subsequently, the analysis is performed on this graph. (Figure 8) shown the graph of interference to noise ratio $\mathrm{I} / \mathrm{N}$ versus distance between HAPS ground station and the ground station for various azimuths in clear-sky condition. It includes the azimuth angles are $30^{\circ}, 60^{\circ}$ and $90^{\circ}$ from (Figure 8), can be seen that interference to noise ratio $\mathrm{I} / \mathrm{N}$ is decreased when the separation distance $\mathrm{d}$ is increasing for various azimuth. A minimum separation distance has been required to obtain the optimum interference to noise ratio $\mathrm{I} / \mathrm{N}$ for the azimuth of $30^{\circ}$, or any azimuth less than $40^{\circ}$, is $188 \mathrm{~km}$. For azimuth of $60^{\circ}, 119 \mathrm{~km}$ is needed. Finally, optimum interference to noise ratio $\mathrm{l} / \mathrm{N}$ at an azimuth equal to $90^{\circ}$, the minimum separation distance is $53 \mathrm{~km}$.

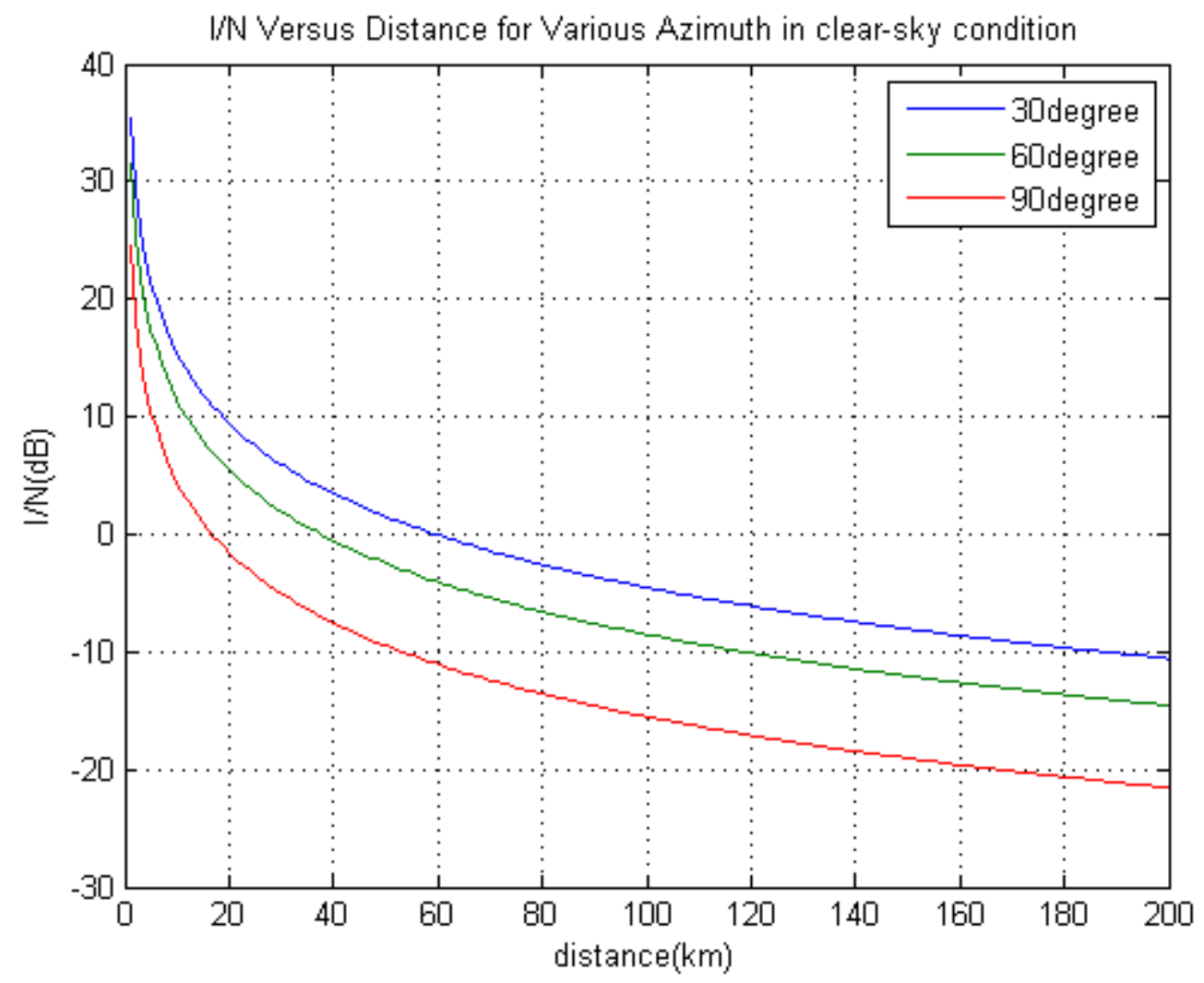

Figure 8: $\mathrm{I} / \mathrm{N}$ vs separation distance for various azimuth in clear sky condition.

The results obtained require to install tow ground stations with elevation angles $30^{\circ}$ and $60^{\circ}$ Assuming the location of fixed service (FS) and fixed service satellite (FSS) to avoid the interference between HAPS ground stations and (FS, FSS), location of the HAPS ground stations will be at (d1 and d2), the interference with FS and FSS stations decrease because user starts to go out of the HAPS coverage area and transmission power of terrestrial station is getting high there for quality of service to improve the chances of coexistence. 


\section{AL-QADISIYAH JOURNAL FOR ENGINEERING SCIENCES}

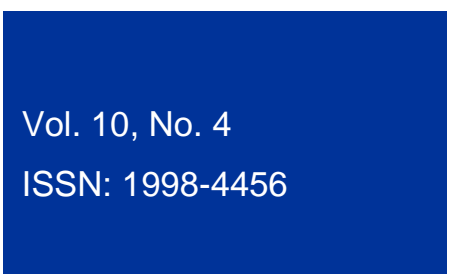

\section{CONCLUSION}

In this paper, have been given in the review of HAPS and the benefits of using HAPS in the wireless communication system in the specific coverage area. Scenario covers the city of Diwaniya, it has been proposed in addition to the two ground stations to communicate with high altitude platform station for more reliability. The mitigation technique has been used to reduce interference to noise ratio $\mathrm{I} / \mathrm{N}$, when the fixed station FS and fixed satellite station FSS is separately away from the HAPS ground station. Most interference exists when the elevation angle from HAPS towards (FSS/GS, FS/GS) stations is equal to the elevation angle from HAPS towards HAPS ground station; the larger gain of fixed satellite station (FSS) and fixed station (FS) lead to reduce interference. Furthermore, the free path loss has been calculated depending on the coverage area of Diwaniyah city. The network of HAPS will be covering a whole city area of different wireless communication service.

\section{REFERENCES}

1. Al-Samhi, S. H. A., and N. S. Rajput. "Interference environment between high altitude platform station and fixed wireless access stations." system 4 (2012), 5.

2. Alsamhi, Saeed H., and N. S. Rajput. "An intelligent HAP for broadband wireless communications: Developments, QoS and applications." International Journal of Electronics and Electrical Engineering 3.2 (2015), pg. 134-143.

3. Alsamhi, S. H. A., and N. S. Rajput. "Methodology for coexistence of high altitude platform ground stations and radio relay stations with reduced interference." International Journal of Scientific \& Engineering Research 3 (2012),pg. 1-7.

4. Cuevas-Ruiz, José Luis, Alejandro Aragon-Zavala, and Beatriz Bautista-Leon. "Co-channel interference for terrestrial and HAPS systems in a cellular structure." Electronics, Robotics and Automotive Mechanics Conference, 2009. CERMA'09.. IEEE, 2009.

5. ITU-R F.1569, "Technical And Operational Characteristics For The Fixed Service Using High Altitude Platform Stations In The Bands 27.5-28.35 GHz And 31-31.3 GHz", (2002).

6. ITU-R Recommendation F.1501, "Coordination distance for systems in the fixed service (FS) involving highaltitude platform stations (HAPSs) sharing the frequency bands $47.2-47.5 \mathrm{GHz}$ and $47.9-48.2 \mathrm{GHz}$ with other systems in the fixed service".

7. ITU-RF.1500, "Preferred Characteristics of systems in the fixed service using High Altitude Platform Operating in the bands 47.2-47.5GHZ and 47.9-48.2 GHz",(2000).

8. Karapantazis, Stylianos, and F. Pavlidou. "Broadband communications via high-altitude platforms: A survey." IEEE Communications Surveys \& Tutorials 7.1 (2005),pg 2-31.

9. Matolak, David W., and Ruoyu Sun. "Unmanned aircraft systems: Air-ground channel characterization for future applications." IEEE Vehicular Technology Magazine 10.2 (2015),pg. 79-85.

10. Tariq, K. R., Majed, M. B., \& Hamid, Z. A "Design of Wireless Communication System to Cover Specific Area by Using HAPS".UHD journal, 1(3) .(2016), pg. 357-361.

11. Tozer, T_C, and David Grace. "High-altitude platforms for wireless communications." Electronics \& Communication Engineering Journal 13.3 (2001), pg. 127-137.

12. Zeng, Yong, Rui Zhang, and Teng Joon Lim. "Wireless communications with unmanned aerial vehicles: opportunities and challenges." IEEE Communications Magazine 54.5 (2016),pg. 36-42.

13. F.1609: Interference evaluation from fixed service systems using high altitude platform stations to conventional fixed service systems in the bands $27.5-28.35 \mathrm{GHz}$ and $31-31.3 \mathrm{GHz},(2003)$.

14. https://electronicsforu.com/technology-trends/wireless-communication-using-high-altitude-platform/2.

15. QucomHAPS Malaysia official website http://www.qucomhaps.net/. 